\title{
The rare finding of a Dieulafoy's lesion at the major papilla
}

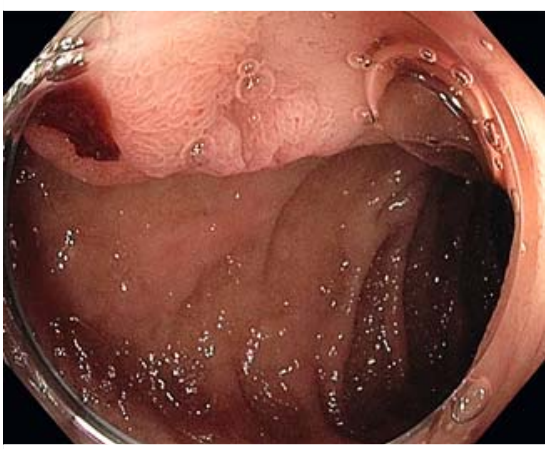

- Fig. 1 Clot at the major papilla adjacent to the bile duct orifice.

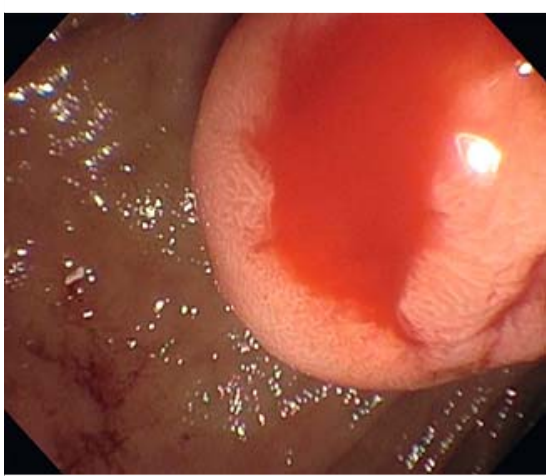

-Fig. 2 Actively bleeding Dieulafoy's lesion.

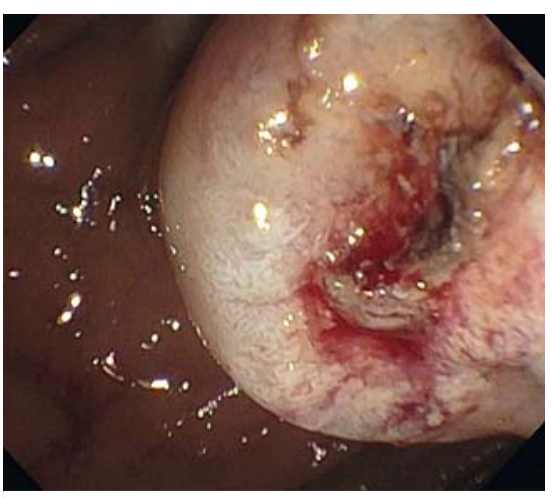

- Fig. 3 Dieulafoy's lesion after endoscopic treatment.

A 58-year-old man with history of diabetes, hypertension, chronic kidney disease, and chronic calcific pancreatitis presented with five episodes of coffeeground emesis and melena. The patient had previously required endoscopic

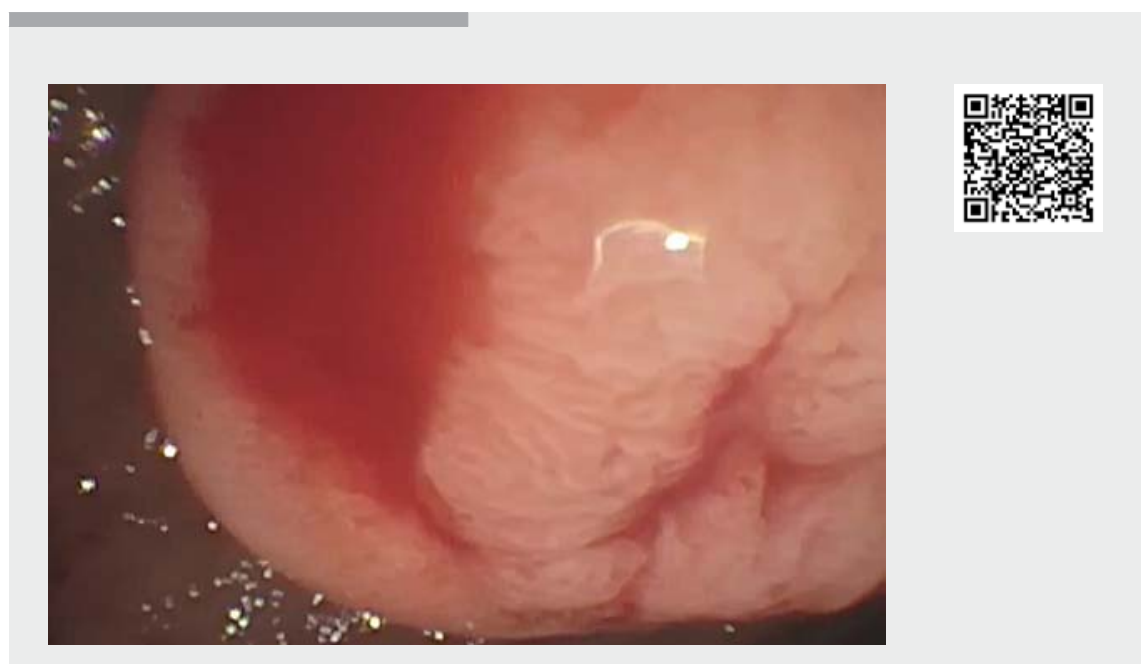

$\nabla$ Video 1 Identification and treatment of Dieulafoy's lesion at the major papilla.

transmural drainage of walled-off pancreatic necrosis 1 year earlier with a lumen-apposing metal stent, which had since been removed.

The patient presented with tachycardia with a heart rate of 125 beats/minute and blood pressure was $107 / 75 \mathrm{mmHg}$. Laboratory examination revealed hemoglobin of $6.8 \mathrm{~g} / \mathrm{dL}$ (baseline level of $13 \mathrm{~g} /$ $\mathrm{dL})$. Upper endoscopy with a forwardviewing gastroscope with a distal attachment cap revealed blood in the second part of the duodenum as well as a clot in the area of the major papilla ( $\triangleright$ Fig.1). Due to concern for hemosuccus pancreaticus from a bleeding pseudoaneurysm, a computed tomography angiogram was performed, which did not demonstrate a pseudoaneurysm or any active bleeding. Subsequent examination with a duodenoscope revealed a pulsatile vessel ( $>$ Fig. 2, \ Video $\mathbf{1}$ ) in the absence of an ulcer, confirming the diagnosis of a Dieulafoy's lesion at the major papilla, which was clearly separate from the bile duct and pancreatic duct orifices.

Endoscopic therapy with epinephrine injection and bipolar cautery was successful in treating the lesion ( $>$ Fig. $\mathbf{3}$ ).
Defined as dilated aberrant submucosal vessels eroding through overlying epithelium without ulceration, Dieulafoy's lesions can present anywhere along the gastrointestinal tract [1]. Typically located in the proximal stomach, Dieulafoy's lesions are exceedingly rare at the major papilla with few reported cases at this location [2]. Risk factors for the development of Dieulafoy's lesions include male sex, hypertension, chronic kidney disease, and diabetes, all of which were noted in this patient [1]. Additional differential diagnoses in this patient would include hemosuccus pancreaticus from a pseudoaneurysm or gastric varices secondary to splenic vein thrombosis [3].

Endoscopy_UCTN_Code_TTT_1AO_2AD

\section{Competing interests}

Dr. Wagh declares he is a consultant for Boston Scientific and Medtronic. Dr. Wani declares he is a consultant for Boston Scientific, Medtronic, Interpace and Cernostics, and is supported by the University of Colorado Department of Medicine Outstanding Early Scholars Program. Dr. Han declares no conflict of interest. 
The authors

Samuel Han, Mihir S. Wagh, Sachin Wani

Division of Gastroenterology and Hepatology,

University of Colorado Anschutz Medical

Campus, Aurora, Colorado, United States

Corresponding author

\section{Sachin Wani, MD}

Division of Gastroenterology and

Hepatology, University of Colorado Anschutz

Medical Campus, Mail Stop F735, 1635

Aurora Court, Rm 2.031, Aurora, CO 80045 , United States

Fax: +1-720-848-2749

Sachin.Wani@cuanschutz.edu

\section{References}

[1] Lara LF, Sreenarasimhaiah J, Tang S] et al. Dieulafoy lesions of the GI tract: localization and therapeutic outcomes. Dig Dis Sci 2010; 55: 3436-3441

[2] Han D, Adler ME, Sejpal DV. Ampullary Dieulafoy: an unusual cause of obscure gastrointestinal bleeding. Clin Gastroenterol Hepatol 2018; 16: A31

[3] Savastano S, Feltrin GP, Antonio T et al. Arterial complications of pancreatitis: diagnostic and therapeutic role of radiology. Pancreas 1993; 8: 687-692

Bibliography

Endoscopy 2021; 53: E44-E45

DOI $10.1055 / \mathrm{a}-1173-8298$

ISSN 0013-726X

published online 5.6.2020

(C) 2020. Thieme. All rights reserved.

Georg Thieme Verlag KG, Rüdigerstraße 14,

70469 Stuttgart, Germany
ENDOSCOPY E-VIDEOS

https://eref.thieme.de/e-videos

口回 Endoscopy E-Videos is a free 然故 access online section, reporting 回舴: on interesting cases and new techniques in gastroenterological endoscopy. All papers include a high quality video and all contributions are freely accessible online.

This section has its own submission website at https://mc.manuscriptcentral.com/e-videos 